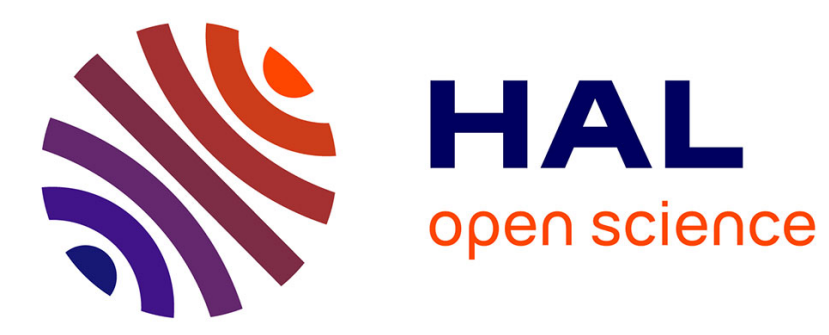

\title{
Investigating mechanical, thermal and rheological properties of polypropylene/carbon nanotubes composites
}

Mohamed Lakdhar Sahli, Thierry Barriere, Xavier Roizard, Mohamed Assoul

\section{- To cite this version:}

Mohamed Lakdhar Sahli, Thierry Barriere, Xavier Roizard, Mohamed Assoul. Investigating mechanical, thermal and rheological properties of polypropylene/carbon nanotubes composites. Microsystem Technologies, 2020, 26 (9), pp.3023 - 3027. hal-02993934

\section{HAL Id: hal-02993934 \\ https://hal.science/hal-02993934}

Submitted on 7 Nov 2020

HAL is a multi-disciplinary open access archive for the deposit and dissemination of scientific research documents, whether they are published or not. The documents may come from teaching and research institutions in France or abroad, or from public or private research centers.
L'archive ouverte pluridisciplinaire HAL, est destinée au dépôt et à la diffusion de documents scientifiques de niveau recherche, publiés ou non, émanant des établissements d'enseignement et de recherche français ou étrangers, des laboratoires publics ou privés. 


\section{Microsystem Technologies}

Investigating mechanical and thermal properties of polypropylene/carbon nanotubes composites

\section{--Manuscript Draft--}

\begin{tabular}{|c|c|}
\hline Manuscript Number: & MITE-D-20-00128 \\
\hline Full Title: & $\begin{array}{l}\text { Investigating mechanical and thermal properties of polypropylene/carbon nanotubes } \\
\text { composites }\end{array}$ \\
\hline Keywords: & Nano-composite material; dispersion; rheology; mechanical properties \\
\hline \multicolumn{2}{|l|}{$\begin{array}{l}\text { Corresponding Author Secondary } \\
\text { Information: }\end{array}$} \\
\hline Corresponding Author's Institution: & FEMTO-ST \\
\hline \multicolumn{2}{|l|}{ First Author Secondary Information: } \\
\hline \multirow[t]{4}{*}{ Order of Authors: } & Mohamed SAHLI, Pr. \\
\hline & Thierry Barrière \\
\hline & Xavier Roazard \\
\hline & Mohamed Assoul \\
\hline \multicolumn{2}{|c|}{ Order of Authors Secondary Information: } \\
\hline \multicolumn{2}{|l|}{ Funding Information: } \\
\hline
\end{tabular}




\title{
Investigating mechanical and thermal properties of polypropylene/carbon nanotubes composites
}

\author{
M. Sahli', T. Barrière ${ }^{1}$, X. Roazard ${ }^{1}$, M. Assoul $^{1}$ \\ 1. FEMTO-ST Institute/Applied Mechanics Department, 24 chemin de l'épitaphe, Besançon, France
}

\begin{abstract}
.
Multi-walled carbon nanotube-polypropylene nano-composite loaded at 0.01 to $5 \mathrm{wt} \%$ of CNTs has been prepared using twin-screw mixer. The rheological and thermo-mecanical properties have been studied using rheometer and tensile machine. The CNTs were well dispersed in PP with fairly good dispersion stability. The effect of the volume fraction of CNT reinforcements on the Young's modulus of the nano-composites is investigated.
\end{abstract}

Keywords: Nano-composite material, dispersion, rheology, mechanical properties.

\section{Introduction}

For the last decade CNTs have been considered as promising nano-sized reinforcing fillers with a random orientation similar to conventional short fiber reinforced composites. In fact, the outstanding thermo-mechanical and electrical properties of these carbon nanotubes (CNTs) have made them among the most promising materials in a wide range of applications [1-3].

However, the incorporation of CNTs in a polymer or ceramic matrix does not result in an outstanding improvement of the corresponding properties of the composite. One of the most difficult problem concerning nanocarbon-filled composites is associated with the dispersion of carbon nanotubes or other nanoparticles into a polymer matrix [6-9]. Good dispersion and intimate contact between the filler and the matrix are major challenges to fully realize outstanding properties of CNTs in composite materials. The nature of the polymer binder also plays an important role in the formation of a composite properties complex. In addition, the twin-screw mixer technique is widely used for incorporation of nano-carbons in highly viscous melts. It's well suited to overwork some of these problems associated with the dispersion of CNTs. This approach allows using moderate shear rates and shear stress, making viscous polymer blends relatively easy to process. Shear stress arises from the screw rotations that provide better dispersion of particle in polymer matrix. Although some experiments have been conducted on material properties of CNT reinforced composites scattered data on the nano-reinforced composites have been reported in 
literature [10-14]. The main reasons for the inconsistency are attributed to drawbacks in the uniform alignment of CNT reinforcements and forming proper interfacial bonding between matrix and CNTs during the mixing process of the composites. Prashntha et al. [15] report on PP-CNTs nanocomposites produced with varying CNTs content by diluting a commercial masterbatch in a twin screw extruder. They show that CNTs enhance tensile modulus and yield stress, while reducing the ductility of nanocomposites systems. Flexural properties increses with CNTs content with maximum benefits observed for $2 \mathrm{wt} \%$ CNTs filled nanocomposites. Szentes et al. [16] compare PP nanocomposites filled with CNTs prepared by single crew extruder and twin screw extruder. By increasing the CNTs content up to $5 \mathrm{wt} \%$, the value of nanocomposites melt flow rate decreases more for simples obtained by twin scew extruder as a sign of a better homogeneity achieved wth process. Xu and Wang [17] showed that the formation of the CNTs network couldmainly restrict the mobility and diffusion of PP chains to crystal growth fronts. Typically, CNTs are considered to be nucleation agents that accelerate PP crystallization, while CNTs networks canimpose physical confinement on polymer crystal growth. Frankland et al. [18] investigated stress-strain curves of single-walled CNTs reinforced polyethylene matrix composites. They reported that long SWCNTs enhance the stiffness of nanocomposites obviously; however, no significant enhancement was observed for short SWCNTs. zhao and coworkes [19] report substantial increase of tensile modulus and strength by adding small amounts of CNTs to a PP matrix in a corotating twin screw extruder.

The aim of this work is to improve mechanical and thermal performance of polypropylene by addition of carbon nanotubes (CNTs). Tensile strength, elastic modulus and elongation at break have been determined from tensile tests and thermal degradation has been followed by thermogravymetric analysis (TGA). In particular, degradation temperature at $0.01 \mathrm{wt} \%$ and $5 \mathrm{wt} \%$ weight loss has been determined as a representative parameter of the degradation improvement.

\section{Experimental Methods}

\subsection{Materials}

The multi-walled carbon nanotubes (NC7000) produced by chemical vapor deposition (CVD) were purchased from Nanocyl Company ${ }^{\circledR}$ (Belgium). The mean diameter of the MWNTs was about $15-30 \mathrm{~nm}$ with the purity of $90 \%$. 
The polymer matrix used to elaborate the nano-composites was a semi-crystalline thermoplastic polypropylene (PP-EP548N) produced by Sabic Company ${ }^{\circledR}$ with melt flow Index $(\mathrm{MFI})=11 \mathrm{~g} / 10 \mathrm{~min}\left(230^{\circ} \mathrm{C} / 2.16 \mathrm{~kg}\right)$ and density $=0.892 \mathrm{~g} / \mathrm{mm}^{3}$.

\subsection{Preparation of nano-composites}

The thermoplastic polypropylene was introduced in the a Brabender ${ }^{\circledR}$ mixer with a pair of rotor blades. Then, CNTs were then introduced, after the melting of the thermoplastic matrix. For the melt mixing process, the rotation speed and temperature of the mixing chamber were set at $30 \mathrm{rpm}$ and $180^{\circ} \mathrm{C}$, respectively, and the blending continued for $30 \mathrm{~min}$. The CNTs concentration was varied as 0 to $5 \mathrm{wt} \%$ with respect to PP to investigate the effect of CNTs concentration on the properties of the composites.

\subsection{Measurements and characterizations}

Thermo-gravimetric/differential thermal analysis (TG/DTA) of CNTs/PP composite were carried out using a thermobalance Setaram ${ }^{\circledR}$ thermal analyzer from room temperature to $500^{\circ} \mathrm{C}$, at a rate of $10^{\circ} \mathrm{C} / \mathrm{min}$ in a continuous argon flow. The rheological analyses were carried out using using rheometer HAAKE MARS III with a cone and plate geometry with the diameter of $35 \mathrm{~mm}$ and the cone angle of $2^{\circ}$. The shear rate has been chosen in a range from $10^{-1}$ to $10^{2} \mathrm{~s}^{-1}$. The test temperature is set from 180 to $210^{\circ} \mathrm{C}$ beyond the melting temperature of polypropylene and below its degradation temperature. Dynamic measurements of rheological properties were carried out using the HAAKE MARS III using parallel plate geometry $(25 \mathrm{~mm}$ diameter and $1 \mathrm{~mm}$ gap). Frequencys weeps from 0.1 to $100 \mathrm{rad} / \mathrm{s}$ were performed. The morphology of CNT nanoparticles and composites were examined by scanning electron microscopy.

\section{Results and Discussion}

\subsection{Nano-composites elaboration}

The curves in figure 1 shows the final mixing torque variation of the PP and CNTs/PP composite (loading ratio from 0.01 to $5 \mathrm{wt} . \%$ ), vs. mixing time. Uniform mixing is achieved when the torque reaches a steady state value. However, increasing the CNTs content can increase the final mixing torque, when the CNTs content is below to $1 \mathrm{wt} . \%$, there is no evident difference comparing to the pure PP; when the CNTs 
content is beyond $1 \mathrm{wt} . \%$, an evident increase of the mixing torque for the composite is observed.

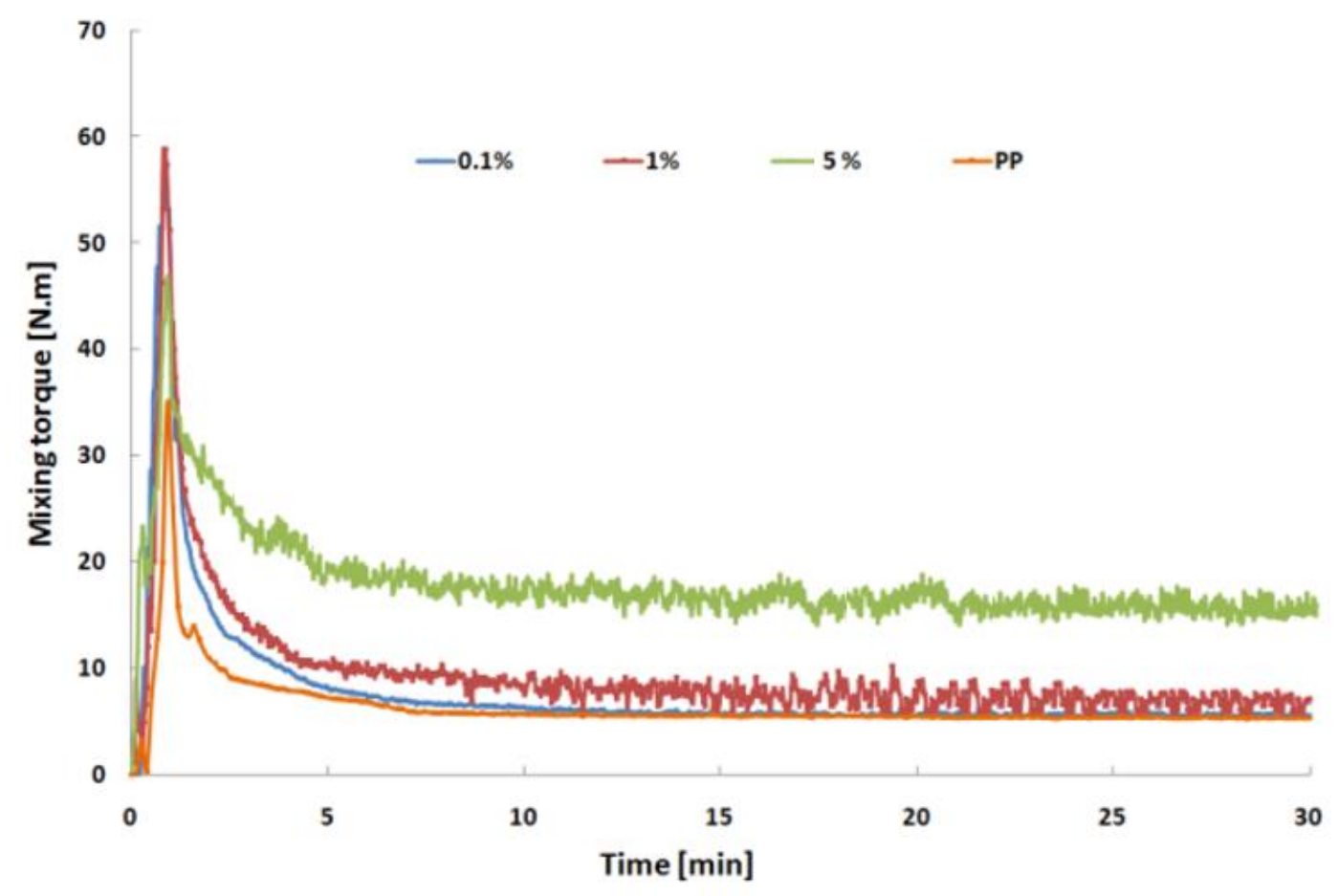

Figure 1. Mixing torque vs. time for PP and PP loaded CNTs at $180^{\circ} \mathrm{C}$ during $30 \mathrm{~min}$.

\subsection{Thermo-gravimetric analysis of nanocomposites}

Thermogravimetric analysis allows assessing the behaviour of materials when subjected to the action of temperature, that's an essential tool for testing the heat resistance of polymeric materials, and therefore evaluating their thermostability. This method can also determine the actual CNTs content in the composites.

In the case of composite, an initial $98 \%$ weight loss at $>350{ }^{\circ} \mathrm{C}$ revealed the oxidation of amorphous carbon present in the sample and also attributed to the decomposition of PP and was degraded completely at $430^{\circ} \mathrm{C}$. A maximum increase of $35^{\circ} \mathrm{C}$ was observed for the $5 \mathrm{wt} . \%$ composite (see Fig.2a).

The incorporation of nanoparticles CNT on PP matrix resulted in an increase in crystallization temperature $\left(T_{c}\right)$. In the case of pristine PP matrix, the $T_{c}$ was observed at $95{ }^{\circ} \mathrm{C}$ and was shifted to $120{ }^{\circ} \mathrm{C}$ for the $5 \mathrm{wt} . \%$ composite. Such an effect on the $T_{c}$ obtained there are also observed on the glass transition and melting temperatures. This indicates also that the thermal stability of the PP nano-particles was improved by the addition of CNT (see Fig.2ba). 

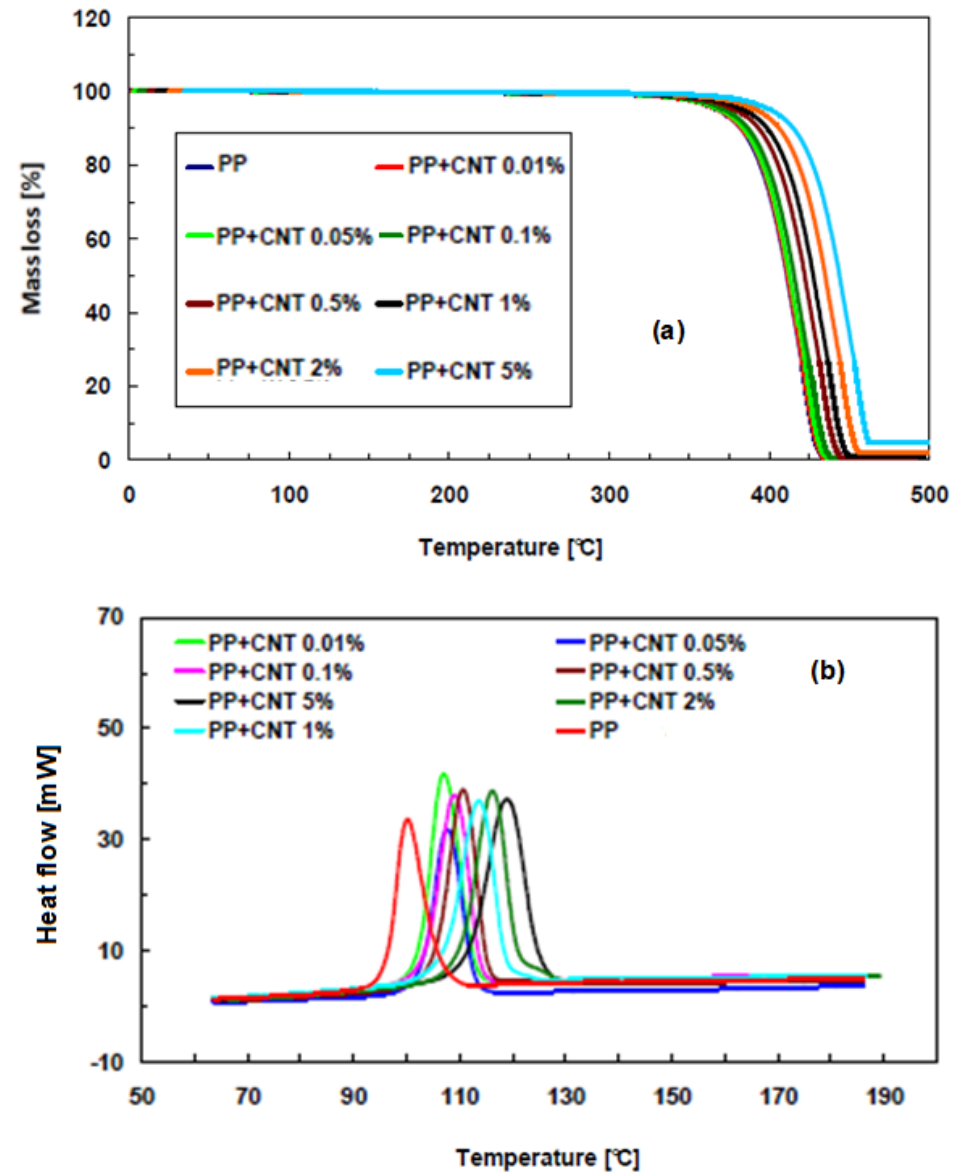

Figure 2. Thermal properties of the CNTs/PP nanocomposite. (a) TGA and (b) DSC analysis.

\subsection{Rheological behaviour of nano-composites}

Figure 3 presents the influence of the CNTs loading ratio to the composites shear viscosity tested at $210^{\circ} \mathrm{C}$. The figure shows that the viscosity of composite increases clearly with a rise of the CNTs loading ratio from $0.1 \mathrm{wt} \%$ to $1 \mathrm{wt} \%$. However, for the CNTs loading ratio of $5 \mathrm{wt} \%$, the viscosity is too high beyond the measurement range of the rheometer. This indicates that the increasing the CNTs loading ratio results in the rise of the composites viscosity which is not conducive to the cavities filling of injection moulding process.

\subsection{Dynamic mechanical analysis of nano-composites}

Fig. $4 \mathrm{a}$, it is shown that the storage modulus and loss modulus of the PP/CNTs composite increases lightly with the increase in CNTs up to $5 \mathrm{wt} \%$. The results shown in Fig. 4b indicate that increasing CNTs concentration leads to a transition from convex to concave curves. Therefore, at sufficiently high concentrations the elastic modulus tends to level off as frequency goes to zero. 


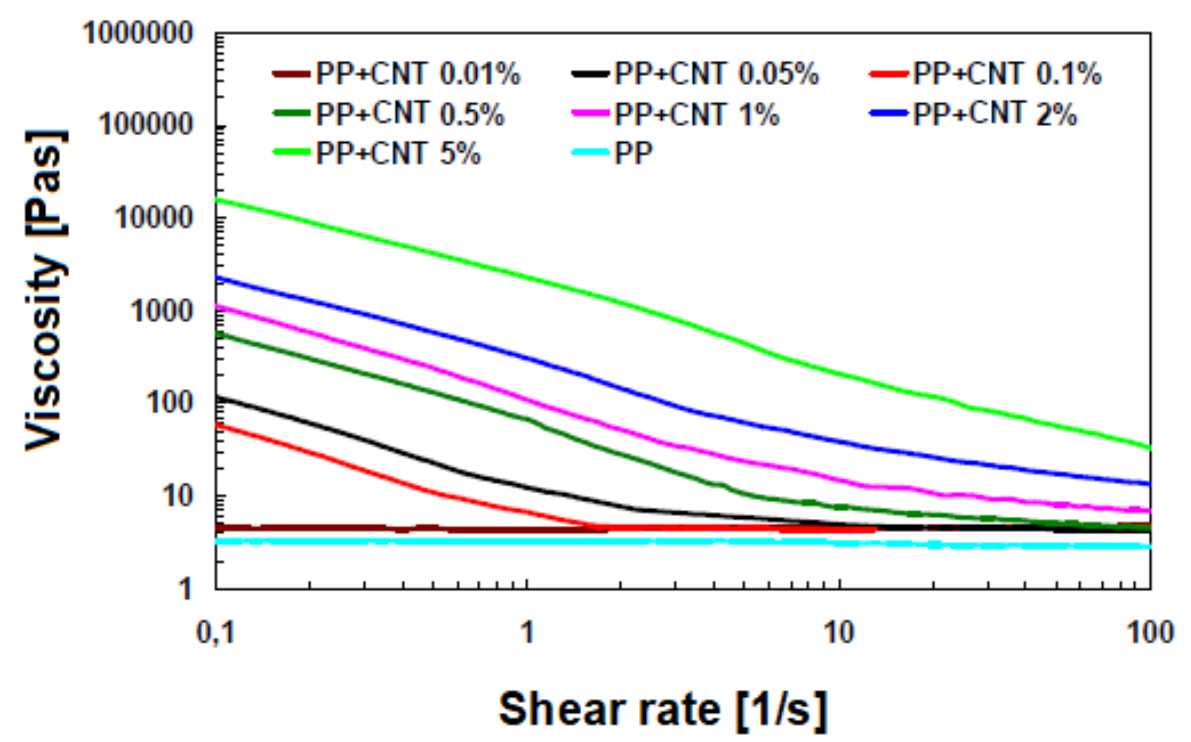

Figure 3. The shear viscosity of nanocomposite vs. shear rate obtained at $210^{\circ} \mathrm{C}$.


Figure 4. Variation of the visco-elastic modulus versus frequency for the nano-compositions at $180^{\circ} \mathrm{C}$. 


\subsection{Morphology study}

According to observations by SEM of elaborated CNT/PP nano-composites, it's difficult to observe the CNT on the surface of materials, because of the density of the matrix is so high what not allow the observation of the fillers. Only clusters of tasks are visible as small white spots (see Fig.5). The CNTs are mostly isolated from each other and uniformly distributed throughout the matrix.
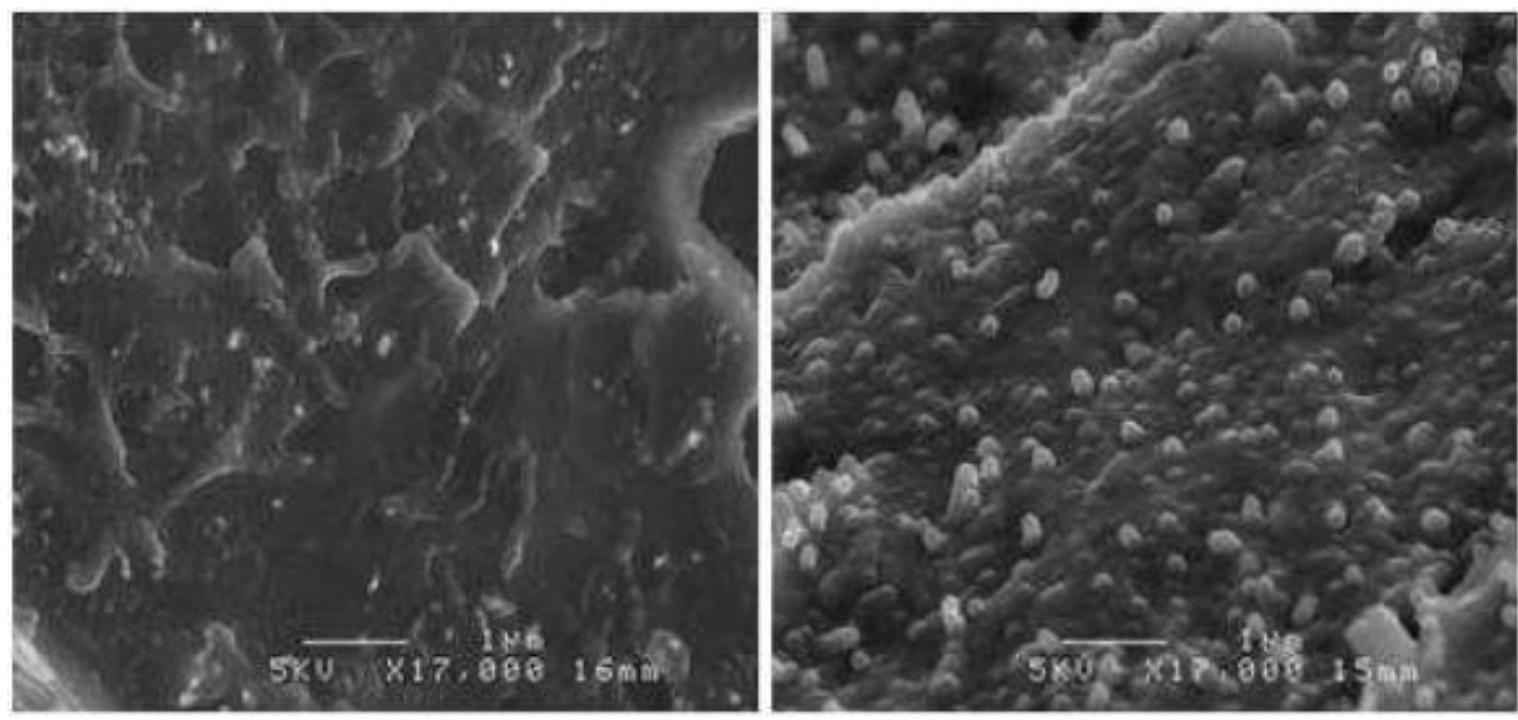

Figure 5. Dispersion of (a) $0.1 \%$, (b) $2 w t \%$ CNTs in nanocomposite.

\subsection{Mechanical characterisation of nano-composites}

The effect of CNTs loading on the tensile modulus of the nanocomposites are presented in Fig. 6. Addition of $0.1 \%$ MWCNT into the composite resulted in enhancement of both modulus and strength by $11.5 \%$ and $32.8 \%$ respectively when tested at room temperature as shown in Fig. 6 . This huge increment in strength might be attributed to the efficient stress transfer from the polymer matrix to the stiff CNTs through the interface. Results indicated also that this tends to stiffen and harden the nanocomposites there by reducing its resilience and toughness. The properties obtained from these stress-strain plots are then reported in Table 1.

\begin{tabular}{ccc}
\hline CNT content (\%) & Young Modulus [GPa] & Resistance a la traction [MPa] \\
\hline 0.0 & $1.37 \pm 0.02$ & $31.06 \pm 0.02$ \\
\hline 0.1 & $1.43 \pm 0.03$ & $31.37 \pm 0.03$ \\
\hline 1.0 & $1.57 \pm 0.05$ & $43.36 \pm 0.04$ \\
\hline 2.0 & $1.63 \pm 0.04$ & $47.53 \pm 0.02$ \\
\hline 5.0 & $1.89 \pm 0.03$ & $68.90 \pm 0.02$
\end{tabular}

Table 1. Properties of composites with varying CNT content at room temperatures. 


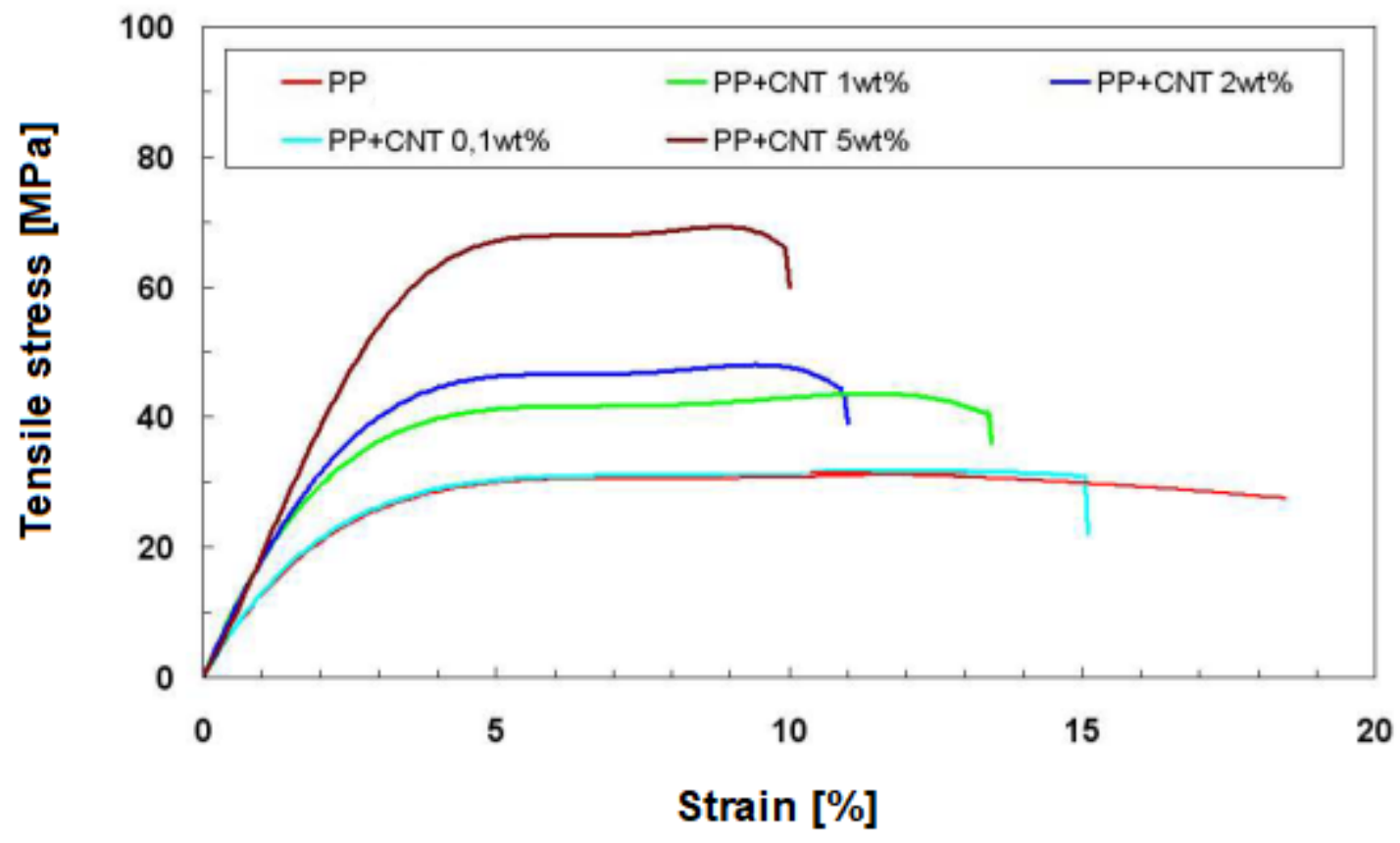

Figure 6. Stress-strain curves for nanocomposites with various CNTs contents at room temperatures.

\section{Conclusion}

This study is focused on the elaboration and thermo-physics characterisations of CNTs/PP nano-composite. The nano-composite specimens with $5 \mathrm{wt} \%$ of CNTs showed improved mechanical properties, with increase in tensile strength and Young's modulus up to 11 and $33 \%$, respectively, with respect to those of the baseline specimens. Otherwise, the experimental results showed also that the thermal stability of the nanocomposites compared with that of the baseline specimen with a fires resistance increased by more than $30^{\circ} \mathrm{C}$.

\section{References}

1. M. Cadek, J. N. Coleman, V. Barron, H. Hedicke, W. J. Blau (2002) Morphological and mechanical properties of carbon-nanotube-reinforced semicrystalline and amorphous polymer composites. Appl. Phys. Lett. $81: 5123-5125$.

2. V. V. Mokashi, D. Qian, Y. A. Liu (2007) A study on the tensile response and fracture in carbon nanotube-based composites using molecular mechanics. Compos. Sci. Technol. 67 :530-540.

3. J. W. G. Wildoer, L. C. Venema, A. G. Rinzler, R. E. Smalley, C. Dekker (1998) Electronic structure of atomically resolved carbon nanotubes. Nature 391:59-62. 
4. J. Gou, B. Minaie, B. Wang, Z. Liang, C. Zhang (2004) Computational and experimental study of interfacial bonding of single-walled nanotube reinforced composites. Comput. Mater. Sci. 31 :225-236.

5. J. L. Tsai, S. H. Tzeng, Y. T. Chiu (2010) Characterizing elastic properties of carbon nanotubes/polyimide nanocomposites using multi-scale simulation. Composites Part B $41: 106-115$.

6. J. Sumfleth, X.C. Adroher, K. Schulte (2009) Synergistic effects in network formation and electrical properties of hybrid epoxy nanocomposites containing multi-wall carbon nanotubes and carbon black, Journal of Materials Science. 44:3241-3247.

7. J. Sumfleth, S.T. Buschhorn, K. Schulte (2011) Comparison of rheological and electrical percolation phenomena in carbon black and carbon nanotube filled epoxy polymers, Journal Material Science. 46 :659-669.

8. F. H. Gojny, M. H. G. Wichmann, U. Köpke, B. Fiedler, K. Schulte (2004) Carbon nanotube reinforced epoxy-composites: enhanced stiffness and fracture toughness at low nanotube content, Compos. Sci. Technol. 64 :2363-2371.

9. S. Zhang, S. Yin, C. Rong, P. Huo, Z. Jiang, G. Wang (2013) Synergistic effects of functionalized graphene and functionalized multi-walled carbon nanotubes on the electrical and mechanical properties of poly(ether sulfone) composites, European Polymer Journal. 49 :3125-3134.

10. M. F. Yu, et al., (2000) Strength and breaking mechanism of multiwalled carbon nanotubes under tensile load. Science 287 :637-640.

11.J. N. Coleman, U. Khan, W. J. Blau, Y. K. Gun'ko (2006) Small but strong: a review of the mechanical properties of carbon nanotube-polymer composites. Carbon 44 :1624-1652.

12.D. Jiang, A. K. Mukherjee (2008) Response to comment on Effect of sintering temperature on single-wall carbon nanotube toughened alumina-based nanocomposite. Scr. Mater. $58: 991-993$.

13. N. P. Padture, W. A. Curtin (2008) Comment on Effect of sintering temperature on a single-wall carbon nanotube-toughened alumina-based composite. Scr. Mater. $58: 989-990$.

14.C. J. Frizzell et al., (2005) Reinforcement of macroscopic carbon nanotube structures by polymer intercalation: The role of polymer molecular weight and chain conformation. Phys. Rev. B 72 :245-420. 
15. K. Prashantha, J. Soulestin, MF. Lacrampe, P. Krawczak, G. Dupin, M. Claes (2009) Masterbatch based multi-walled carbon nanotube filled polypropylene nanocomposites: assessment of rheological and mechanical properties. Comput. Sci. Technol., 69:1756-1763.

16. A. Szentes, G. Horvath, Cs. Varga (2010) Mechanical properties of polypropylene multiwalled carbon nanotube composites. Hung. J. Ind. Chem., 38:67-70.

17. D. Xu, Z. Wang (2008) Role of multi-wall carbon nanotube network in composites to crystallization of isotactic polypropylene matrix. Polymer, 49 :330-338.

18. S. J. V. Frankland, V. M. Harik, G. M. Odegard, D. W. Brenner, T. S. Gates (2003) The stress-strain behavior of polymer-nanotube composites from molecular dynamics simulation. Compos. Sci. Technol. 63 :1655-1661.

19.P. Zhao, K. Wang, H. Yang, Q. Zhang, R. Du, Q. Fu (2007) Excellent tensile ductility in highly oriented injection moulded bars of polypropylene/carbon nanotubes composites. Polymer, 19:5688-5695. 